\title{
3D Printing in Architecture, Engineering and Construction
} (Concrete 3D printing)

\author{
Dr. Ahmed Saleh Abd Elfatah \\ Assistant Professor at Faculty of Engineering, Helwan University \\ engasa@hotmail.com
}

\begin{abstract}
One of the new developments in construction and architecture is 3D Printing with a concrete-like material. This technique can create the opportunity for personalization of large-scale projects for the lower and middle class since it removes the restrictions on shape, that are present in the traditional way of building. The technology also has shown potential in a wide range of disciplines, but the building industry is still behind in the development of 3D printing.

The influence of 3D printing in building industry must not be underestimated as it can reduce various determining factors such as the construction process, material costs and the time span of the whole project. By studying new printable materials and optimizing shapes including the typical properties of 3D printed concrete, the potential of this promising technique can be realized in practice. This research focuses on the background of this new technique, potential applications and future of 3D Concrete Printing.
\end{abstract}

KEYWORDS: 3D Concrete Printing (3DCP), Additive manufacturing, Contour Crafting (CC), Architecture, Engineering and Construction (AEC).

\section{INTRODUCTION}

Additive manufacturing is the new method of creating products from materials such as plastic, sand, and other powdered materials. The process of Additive manufacturing has been used since the mid-1960s and there have been various improvements in terms of materials used in the process of additive manufacturing. Additive manufacturing that is commonly known as 3D printing nowadays has been very efficient in cost reduction of manufacturing and reduction of waste in the process of manufacturing.

In this research, the methods and types of 3D printing and their feasibility in using concrete as a material in the process of making 3D printed concrete products are analysed. 3D printing has been one of the fastest growing technologies in the world presently. The concept of 3D printing has evolved since the 1980s, but not many researches have focused on the concrete 3D printing technologies. The advantages of using concrete as a construction material are durability and it can withstand any natural disasters such as rain, snow and wind and provide shelter to live in. Dr. Behrokh Khoshnevis, a researcher from the University of Southern California, developed a system called Contour Crafting (CC) in mid-2000s that paved the way for the present day's 3D Concrete Printing (3DCP). This Contour crafting has been 
adopted widely by various research institutes to produce massive $3 \mathrm{D}$ printed structures. The use of $\mathrm{CC}$ in building industry can reduce the amount of physical labour used for projects and reduce construction wastes as well. The efficiency of $3 \mathrm{D}$ printing concrete is described later in this research.

\subsection{Research Aims}

The main aim of this research is to evaluate the feasibility of concrete for 3D printing, to emphasise the impact of this new technology for future construction and to encourage the use of concrete in 3D printing thereby reducing costs of construction and increasing the rate of productivity in construction industry.

\section{Additive Manufacturing}

Additive Manufacturing (AM) is a process in which three-dimensional objects are made by adding layer-by-layer of material. The materials used can be plastic, metal, concrete etc. The commonly used AM technologies include the use of a computer, 3D modelling software (Computer Aided Design or CAD), machine equipment and layering material ${ }^{[1}$. Once a CAD sketch is produced, the file is then transferred to the AM equipment and the machine reads the data from the CAD file and starts to lay down the material in layers on top of each other forming the object in three dimensions. The materials used to create these objects can be powder, liquid or sheet metal. The term Additive Manufacturing includes several technologies that can produce similar objects rapidly such as Rapid Prototyping (RP), Direct Digital Manufacturing (DDM), Layered Manufacturing (LM) and 3D printing .

\subsubsection{D printing}

3D printing is an additive manufacturing process of making threedimensional solid objects from a digital file. The materials used to produce the object are different types of hard plastic, metal, concrete, carbon fibre, food ingredients etc. The use of 3D printing has evolved in the recent years with the technological advancement in engineering sector ${ }^{[2]}$.

\subsubsection{D printing in Architecture and Construction}

3D printing architecture models have become an interesting alternative. Typically, architectural models are made of cardboard, wood or other moldable materials. Architects need models to study the aspects of their design. It is often changed to get a perfect concept of their idea in both architectural design and interior design. 3D printing at a construction scale will have a wide variety of applications within the private, commercial, industrial and public sectors. Potential advantages of these technologies include faster construction, lower labor costs, increased complexity and/or accuracy, greater integration of function and less waste produced. Several different approaches have been demonstrated to date which include on-site and off-site fabrication of buildings and construction components, using industrial robots, gantry systems and tethered autonomous vehicles ${ }^{\left.{ }^{3}\right]}$. Demonstrations of construction 3D printing technologies to date have included fabrication of housing, construction components (cladding and structural panels and columns), bridges and civil infrastructure, artificial reefs, follies and sculptures. It 
might also enable construction to be undertaken in harsh or dangerous environments not suitable for a human workforce such as in places with special conditions ${ }^{[4]}$.

\subsubsection{D printed buildings}

A building consists of many parts, such as foundation, walls, windows and doors, ceiling, roof, plumbing and wiring and no company prints whole houses. In construction industry, 3D printing can be used to create construction components or to 'print' entire buildings, when we say, "to print a building," we only mean printing walls of a building, because the printer doesn't yet participate in other processes until now. Really, believe that 3D printing construction can heavily replace traditional construction. Now, traditional stone construction of blocks and bricks is the most threatened one. Materials used in printing buildings contain a mixture of cement and sand, so a printed house is not different from a concrete house ${ }^{[5]}$. The printer is just a way of laying down the material. The only difference is that the printer is a machine or robot, an automated system that eliminates the human factor. Therefore, concerns about the durability of printed houses are not justified.

\subsubsection{D Printing in Interior Design}

Many architects and interior designers are extensively using 3D printing to create new and unique designs that give the overall ambience of a property with a truly modern and cosmopolitan look. With new design flexibilities with 3D printing, designers are now not constrained by any technical limitations for any object. They use 3D printed organic vessels made of salt polymers to indoor, while the exterior cladding is composed of polymer printed blocks (Fig. 1). They can unleash the best of their creativity and make unique designs that were not previously possible with conventional manufacturing techniques ${ }^{[6]}$.
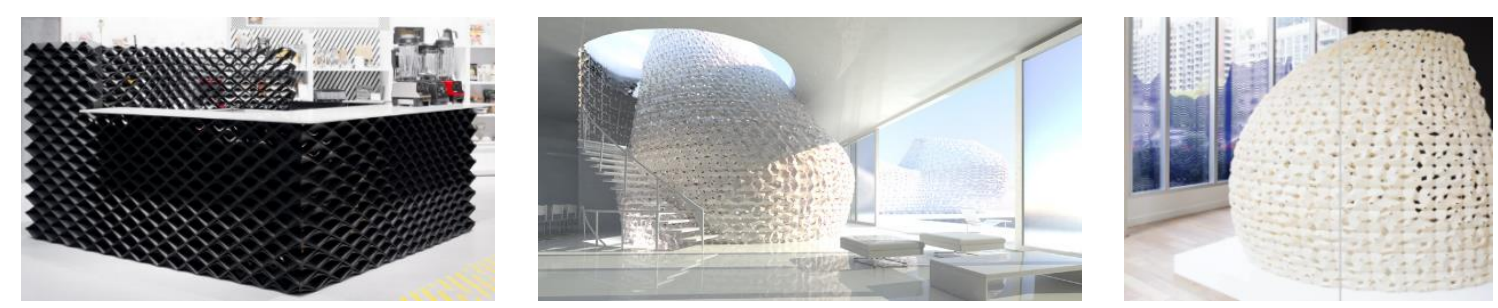

Fig. (1) Shows an interior space made of $3 \mathrm{~d}$ printed mixture obtained by salt and glue constituting an efficient, translucent and inexpensive material https://www.archdaily.com/890494/interior-design-and-3d-

In fact, 3D printing also saves a lot of time as manufacturing a single part can be done in a matter of hours against the days and weeks needed for traditional methods. They no longer need to solely depend on whatever is available in the market; these designers also have the freedom to let the clients choose the colour and size of the product while keeping the design the same ${ }^{[5]}$. With easier access to $3 \mathrm{D}$ printing, architects and interior designers are not in need for searching for completing their designs because material selection is slowly but surely becoming an obligatory part of the interior designing process with using 3D printing.

\subsubsection{D printed bridges}


The first pedestrian bridge printed in 3D in the world is in Spain. The 3D printer used to build the footbridge was manufactured by D-Shape. The 3D printed bridge reflects the complexities of nature's forms. It was developed through parametric design and computational design, which allows to optimize the distribution of materials and allows to maximize the structural performance, being able to dispose the material only where it is needed, with total freedom of forms ${ }^{[7]}$. The bridge has a total length of 12 meters and a width of 1.75 meters representing a milestone for the construction sector at international level, as large-scale 3D printing technology has been applied in this project for the first time in the field of civil engineering in a public space (Fig. 2).
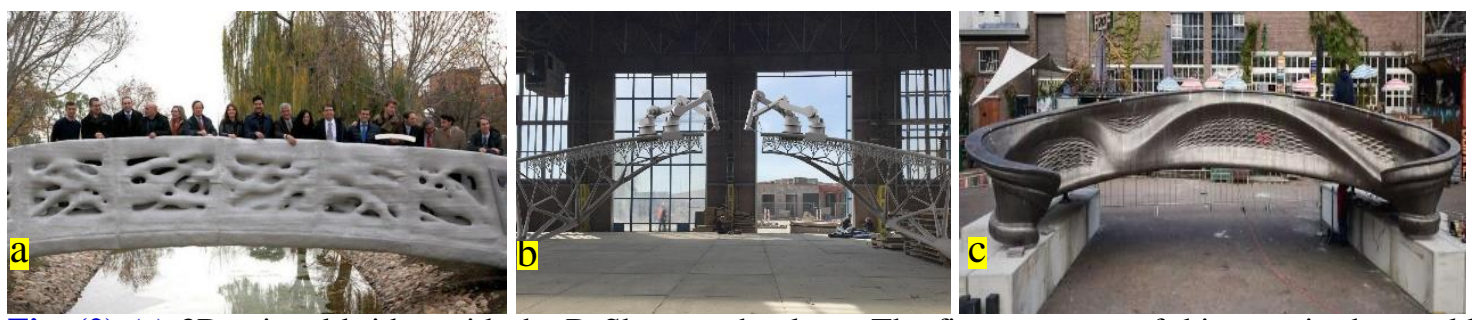

Fig. (2) (a) 3D printed bridge with the D-Shape technology. The first structure of this type in the world [7], (b) 3D-printed steel bridge in the heart of Amsterdam 3D-printed steel bridge in the heart of Amsterdam, (c) the first 3D-printed steel bridge. In 2015, Dutch 3D printing company MX3D ${ }^{[8]}$.

\subsubsection{Extraterrestrial printed structures}

The printing of buildings has been proposed as a particularly useful technology for constructing off-Earth habitats, such as habitats on the Moon or Mars. As of 2013, the European Space Agency was using regular 3D printing technology ${ }^{[8]}$.

The architectural firm proposed a building-construction 3D-printer technology in January 2013 that would use lunar regolith raw materials to produce lunar building structures while using enclosed inflatable habitats for housing the human occupants inside the hard shell printed lunar structures. Overall, these habitats would require only ten percent of the structure mass to be transported from Earth, while using local lunar materials for the other 90 percent of the structure mass ${ }^{[9]}$.

\subsection{D printing technology and materials}

There are varieties of 3D printing materials used at construction scale. These include the following main methods and materials: extrusion (concrete/cement, wax, foam, and polymers), powder bonding (polymer bond, reactive bond, sintering) and additive welding. Many different implementations, conditions and variants of buildings, in particular the specific conditions of the construction site should be taken into account. While designing a mortar mixture intended for use in 3D printing technology, it should be noted that this mixture meets the accepted criteria and design assumptions. It is possible to determine the principles, the composition of mortar mixtures and its required properties. (Fig. 3) ${ }^{[10]}$.

Material, designed and used in 3D printing technology for construction, depends on three interpenetrating factors: raw materials, methods of application and methods of production. While designing such a material, it is also necessary to pay attention to the properties that the manufactured object must fulfil and that it is possible to print by the given printer. The composition of the mixture is also influenced by climatic conditions at the place of object's production, as they affect its composition and maturing conditions ${ }^{[7]}$. 
DR/ Ahmed Saleh /Engineering Research Journal 162 (June 2019) A5- A18

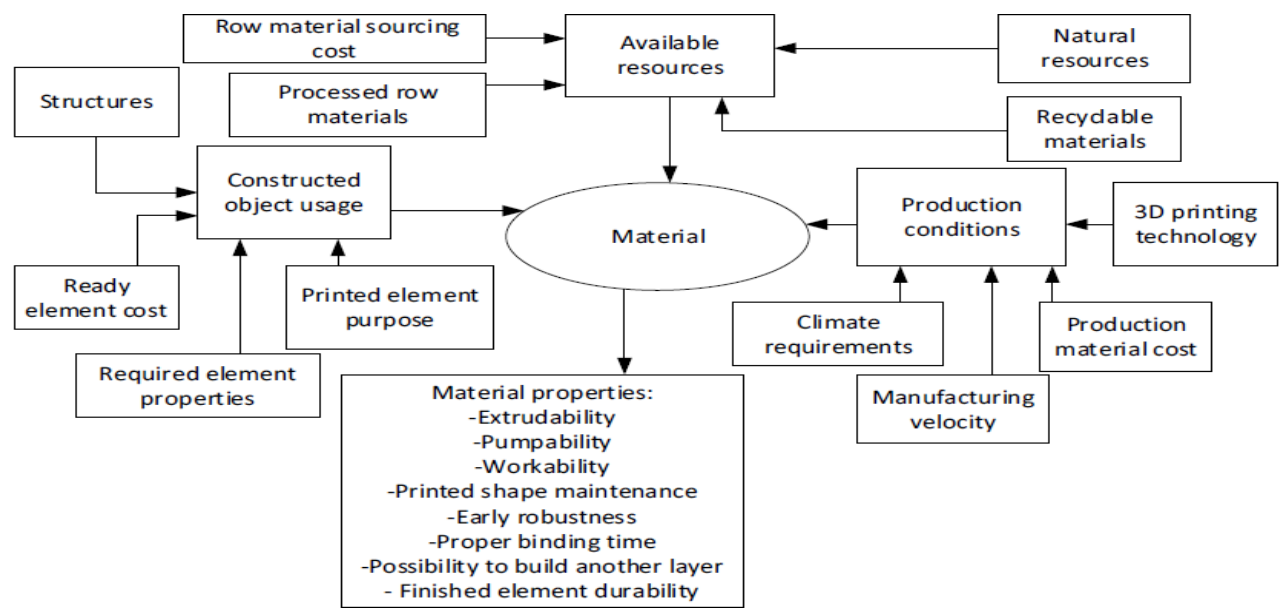

Fig. 3 Building material composition for $3 \mathrm{D}$ printing and properties requirements $[10\rfloor$

The time of achieving the given properties also affects the printing process; it also depends on the method of material delivery and the time of applying subsequent layers of building material [10]. Attention should be paid to such parameters as: flowability of the mixture, extrudability, stability of the printed shape, bonding time, and strength and shrinkage of concrete. The 3D printer concrete is now the most common and testing for maximum utilization in construction industry. So, the more materials used in construction industry are, the more common is a concrete composite. The $3 \mathrm{D}$ printing construction company $\mathrm{CyBe}$ uses a specially designed mortar that sets within three minutes of being printed and dries in one hour. Many companies currently use or are developing a concrete mix made with recycled materials. Construction company Cazza's mix is made from up to 80 percent recycled material ${ }^{[4]}$.

\section{Concrete 3D printing}

The steps of 3D printing an object with concrete consists of three steps: preparation of data, preparation of concrete mix and printing of the object. In the data preparation stage, the spatial model of the object to be printed is created in $\mathrm{CAD}$ format. The object is then sliced into layers using one of the slicing softwares. The software creates a plan for the 3D printer for laying the concrete in layer-bylayer form. The next stage is the preparation of the concrete mix and management of feeding of concrete to the 3D printer (Fig. 4). (The mixture is automated and flows into the printer continuously) ${ }^{[11]}$.

At the third stage, the concrete mixture is pressed out of the printer through

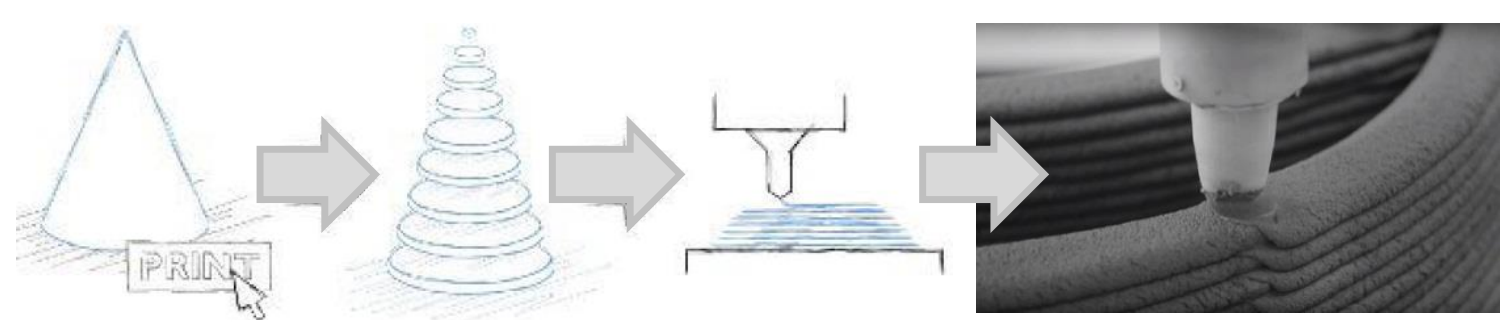

Fig. 4 Concrete $3 D$ printing process \& Concrete extrusion process

the nozzle and placed in layers. The concrete flows through the nozzle of the printer on a prescribed path programmed by the user to the 3D printer. This path is programmed accordingly so that the printer lays the concrete in layer-by-layer fashion, forming a real three-dimensional object from the digital model ${ }^{[11]}$. The workability of the concrete plays a vital role in this stage of the printing. The workability is responsible for both the extrudability and buildability aspects of concrete. 


\subsection{Concrete 3D printers}

Concrete 3D printing could be used in many ways in construction industry. One option is to print elements in the factory, and then they are transported to construction sites and assembled. Another option is to set up the printer on a construction site where the structure is printed in elements on the site and assembled together, or directly print the structure on site. Two types of printers are currently in use in the industry. The first type is a framed printer. This kind of printer would fit only in factories because it is very difficult to transport and assemble this kind of printers (Fig. 5). The disadvantage of this printer is that the frame of the printer must be larger than the structure itself. The larger frame makes the printer expensive and difficult to transport and assemble. ${ }^{[12]}$

The second type of printer is a non-framed concrete printer. It is a robotic printing arm mounted on a vehicle. This kind of printer can be easily transported and does not require flat ground, unlike the framed printer (Fig. 6). This kind of non-framed 3D printer is used by $\mathrm{CyBe}$ constructions in the Netherlands ${ }^{[13]}$.
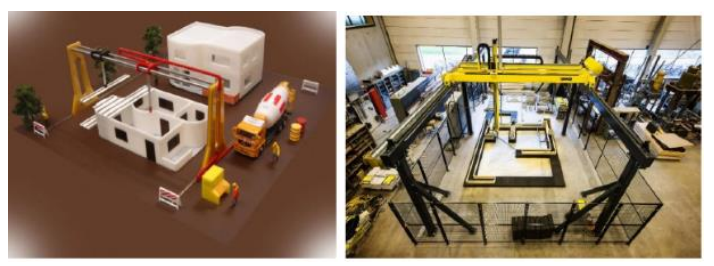

Fig. 5 Framed concrete 3D printers Source: https://www.tue.nl/en/university/departments/builtenvironment/research/research-programs/structuraldesign/research/research-areas/concrete-research-
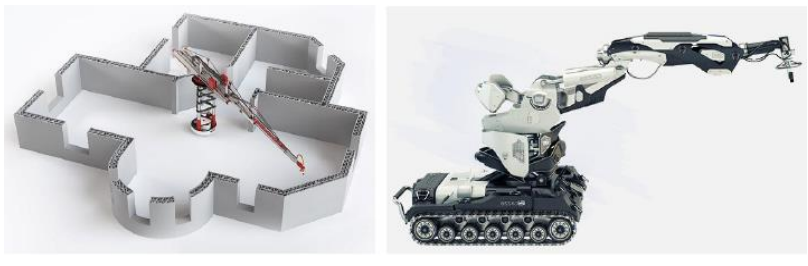

Fig. 6 Non-framed concrete 3D printers Source: $\quad$ https://3dprint.com/189228/cazza-3d-printconstruction-robots/

Traditional methods vs 3D printing

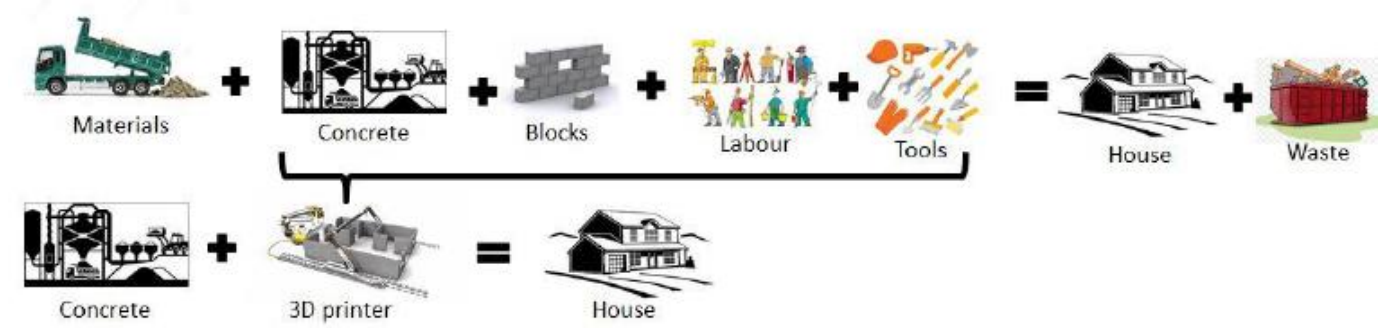

Fig. 7 Traditional production process vs 30 printing ${ }^{\text {14. }}$

The illustration above shows clearly the various stages of construction of a structure according to the traditional techniques. They involve human resources in different locations of the structure. Thus, they are time-consuming and expensive. The 3D printer on the other hand shows how the printer is both a tool and a manufacturer ${ }^{[4]}$. The less involvement of the user in the printing process, the smoother the process is automated.

\subsection{Parameters affecting 3DCP}

As summarised in (Fig. 8), the printing process is affected by a multitude of parameters. The three main categories are the computer-aided design, printing process and material behaviour. These categories have a significant influence on one another ${ }^{[14]}$.

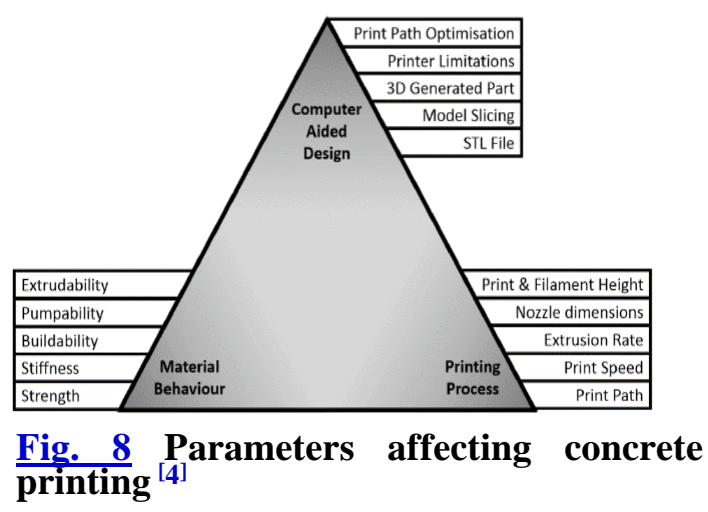




\subsubsection{Computer-aided design for 3D printing}

The typical workflow of concrete 3D printing starts with CAD modelling of the object to be manufactured, as illustrated in (Fig. 9). Next, the CAD model is exported to a conventional 3D data format, typically a STL file format. The STL file is then sliced via software and converted to a machine-readable language before being input to the printer. The printer then proceeds to manufacture the desired 3D object. It is important to consider the physical process of $3 \mathrm{D}$ printing and its limitations, which are not evident during the computer-aided design process ${ }^{[15]}$. For example, the design process should also consider the printer speed, nozzle dimensions, layer thickness, material behaviour and the extrusion capacity of the

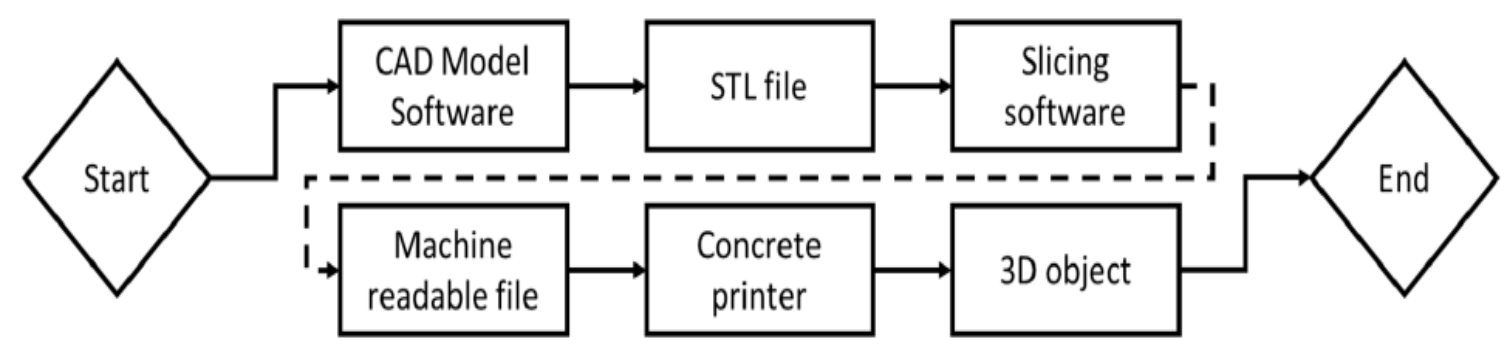

Fig. 9 Modelling workflow of concrete 3D printing ${ }^{[15]}$.

pump.

\subsubsection{Printing process}

The physical printing process is subject to a multitude of parameters, namely the print speed, filament extrusion rate, nozzle dimensions, the printing path, filament height and print height.

The quality of the end product, produced through the concrete printing process, is strongly correlated to the effective Filament height (h0), layer height (Ln) and print height $(\mathrm{H}){ }^{[16]}$. control of these parameters ${ }^{[16]}$.

\subsubsection{Material behaviour}

The fresh state material behaviour of printable concrete influences its extrudability, buildability, pumpability, stiffness and strength. Figure no. 10 illustrates where these properties come into play throughout the concrete printing system ${ }^{[17]}$. The fresh state material behaviour is currently a focus point in concrete printing research. Various studies report a trial and error methodology to determine the optimum printable concrete mix composition. However, none report the use of coarse

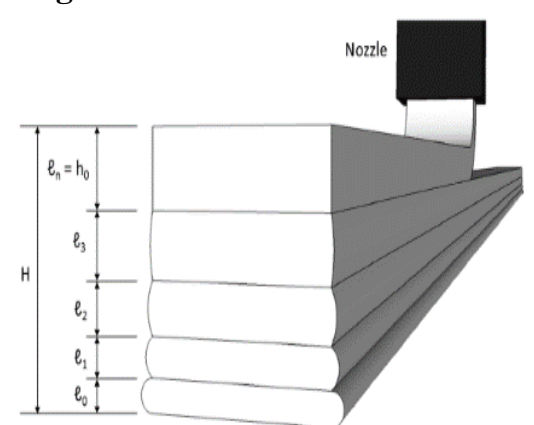
aggregate for printable concrete ${ }^{[14}$. Typically, the particle sizes are limited to less than $2 \mathrm{~mm}$. 


\subsection{Challenges of concrete printing}

Concrete printing and other AM processes still have a multitude of challenges to overcome, before they are adopted for widespread use. This includes accurate material delivery and placement, in addition to control and measurement of material phase transitioning, from its fresh state to hardened state. Furthermore, the layering of concrete could cause the formation of "cold joints" which refer to insufficient bonding between layers reducing structural strength, in turn. The inclusion of steel or fiber reinforcement is another matter requiring attention, as is the surface finish of the product ${ }^{[181}$. Moreover, standardized requirements, benchmarks and testing procedures are yet to be developed to validate the safe and sustainable use of concrete printing as a construction method. The following key properties of concrete need improvement in order to successfully 3D print concrete structures:

- Extrudability.

- Flowability.

- Buildability.

- Open time and

- Contact between layers

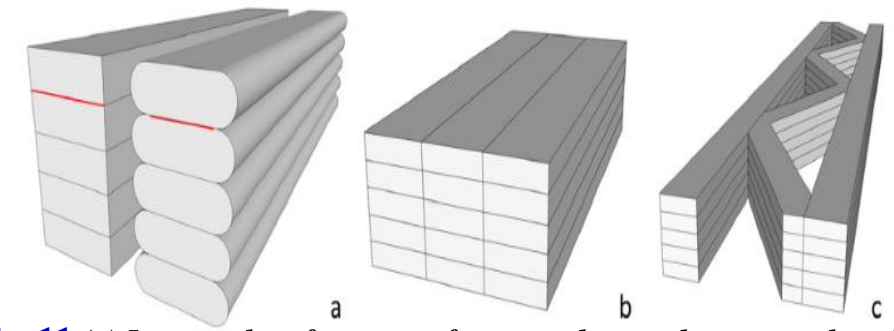

Fig. 11 (a) Increased surface area of rectangular nozzle compared to circular; (b) Increased number of adjacent layers; (c) Supporting cellular structure ${ }^{[18]}$.

\section{3D Construction Printing: a worldwide overview}

Several research groups of research organizations are involved in the development of large-scale 3D printers for the construction industry. The technologies developed differ in terms of printing techniques and materials. The Concept of three-dimensional (3D) printing of concrete has been experimented since the mid 1990's. The generically name 3D Concrete Printing varies with various research groups and enterprises around the world. The projects presented below are experimental and commercial projects that are ongoing on 3D Concrete Printing (3DCP) by various production units and academic institutions around the globe. Tables no. (1, 2, 3, and 4) show the above according to the following factors:

$\checkmark$ Printer Type: Powder bed or layer by layer

$\checkmark$ Movements: Typical movement systems for the printhead

$\checkmark$ Location: In SITU or off site

$\checkmark$ The Printed Object: Load bearing or Hollow

$\checkmark$ Other printer types/technologies 
Table. 1 3D Construction Printing a Worldwide overview (researcher)

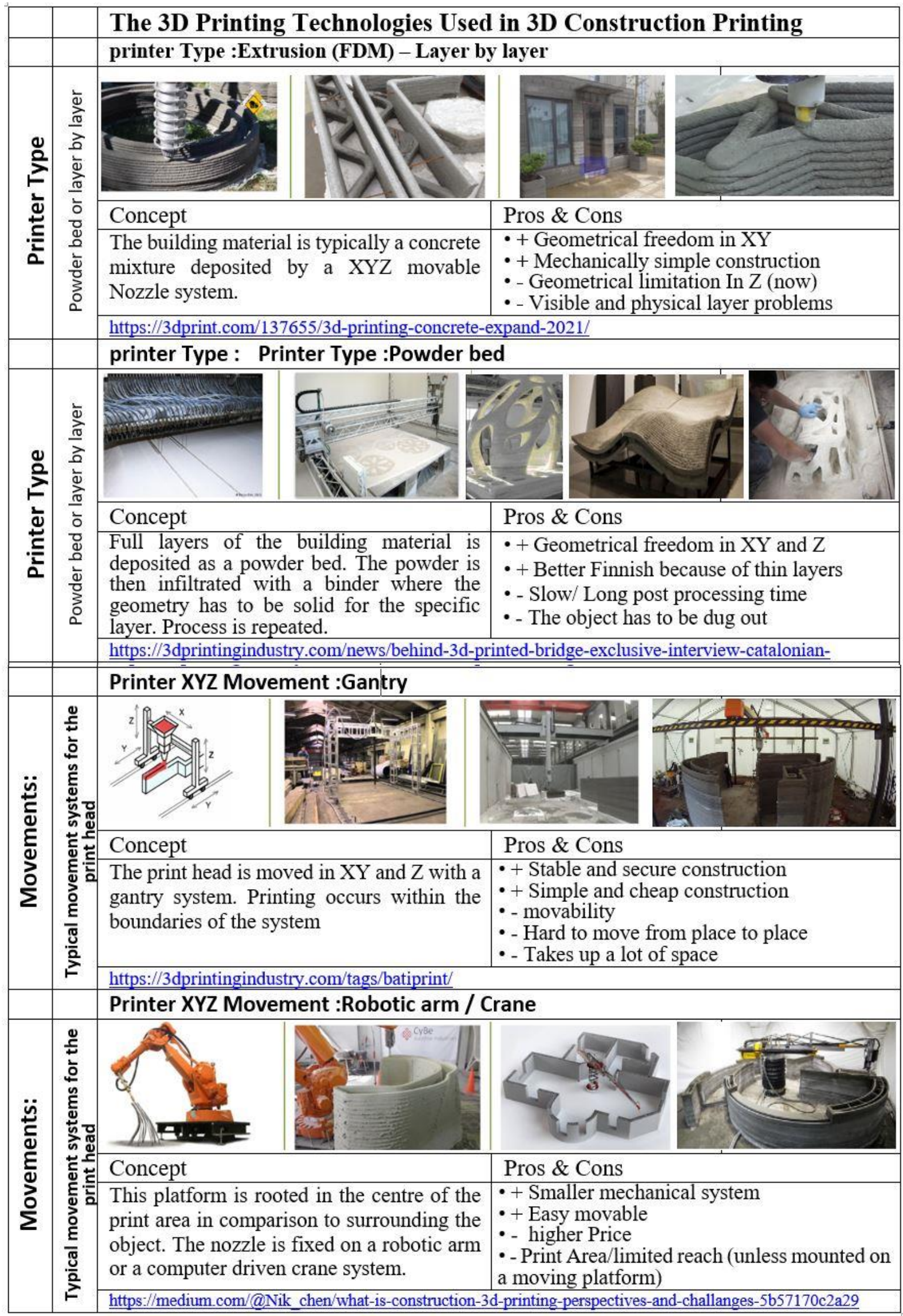


Table. 2 3D Construction Printing a Worldwide overview (researcher)

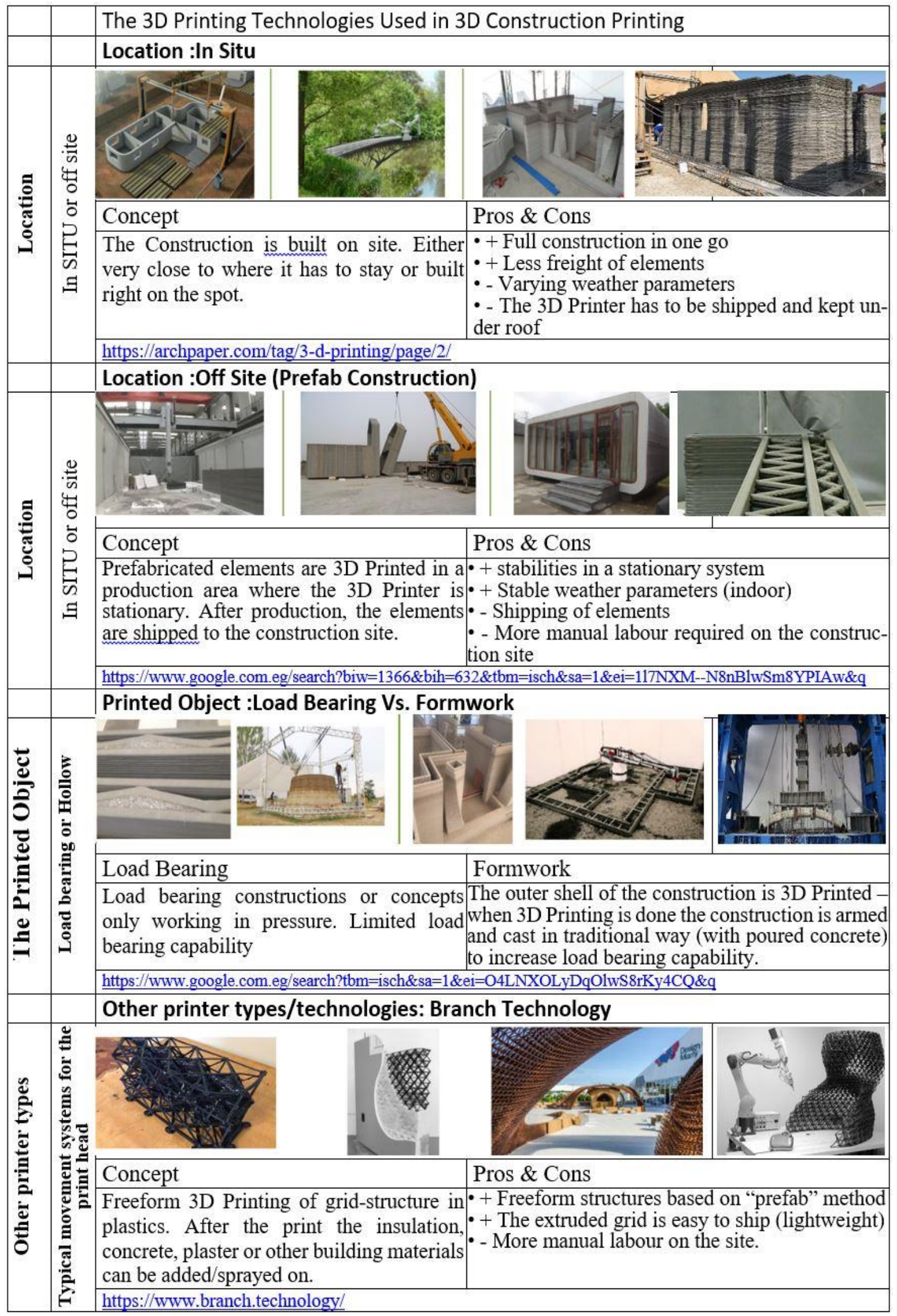


Table. 3 3D Construction Printing: a Worldwide overview

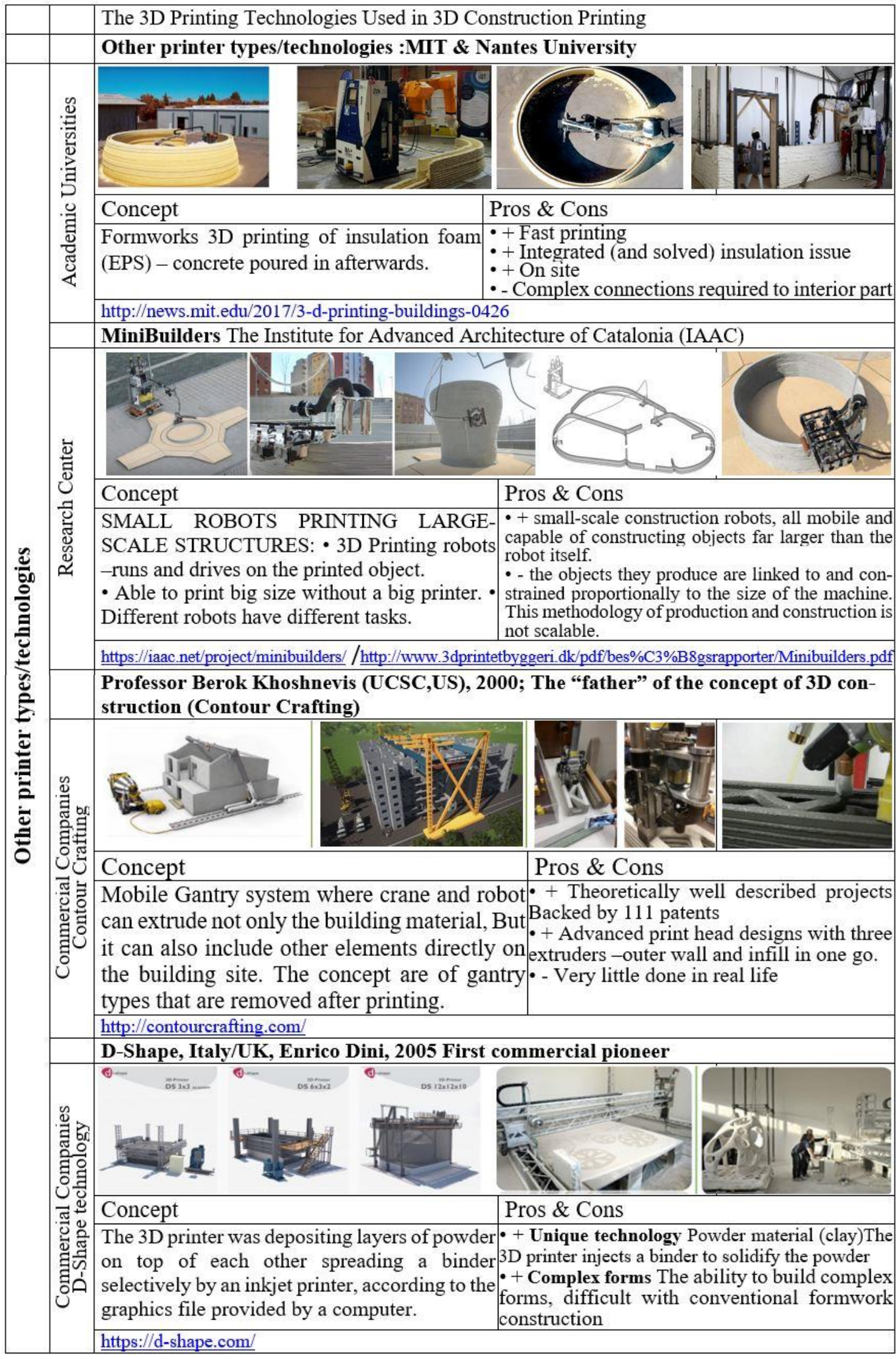




\section{Costs and Benefits of Concrete 3D Printing in Construction Industry}

\subsection{D Construction Wall Printing Calculator}

Since every 3D printing technology makes use of a different material, there are many categories and price ranges. It's hard to give an exact price of a 3D printed building in 2018, as the price depends on the structure's size and complexity. As time progresses, more and more companies will adopt 3D printed buildings. This, combined with developing technologies, will bring prices down and quality up. In addition, that's great news if it means more access to safe, affordable shelter for those in need. Table. 4 shows a formula that will calculate the cost, time and material usage for a 3D construction wall project, based on 12 input factors.

5.1.1. Cost calculation in 3D printing vs the Traditional methods (per $\mathrm{m}^{3}$ concrete)

The BOD, which is short for "Building on Demand" is named precisely so to underline that with 3D printing technology applied for building projects, the building process is automatized and the borders for what can be made are hereby expanded. Even if the BOD is less than a $50 \mathrm{sqm}$ building, it is still large enough to illustrate some of the economic and architectural advantages of applying 3D printing technology to constructions. With traditional building techniques, any shape that is organic or not straight is a challenge, technically as well as with respect to costs. The BOD does not contain any straight walls, the only straight elements being the windows and doors.

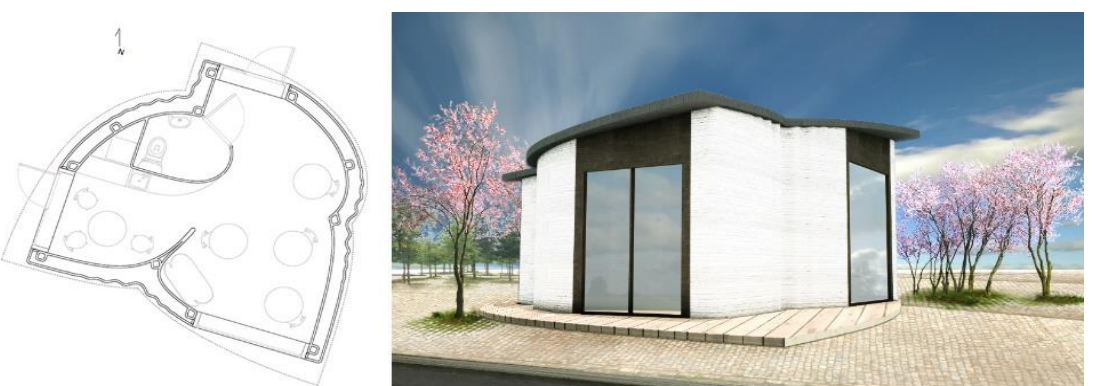

Fig. 12 The BOD is a small 3D printed office hotel of less than 50 square meters located in Copenhagen's

Nordhavn https://cobod.com/thebod/

Table.4 Excel sheet for cost calculator Concrete 3D printers Cost Calculator: Input Variables are RED BOLD (00), everything thing else is a calculation result.

\begin{tabular}{|c|c|c|c|c|c|c|c|}
\hline \multirow[t]{3}{*}{1} & \multicolumn{7}{|c|}{ BUILDING SPECIFICS } \\
\hline & \multicolumn{3}{|l|}{ Total m2 of exterior wall * } & $\mathbf{0 0}$ & \multicolumn{2}{|c|}{ Total m2 of interior wall * } & 00 \\
\hline & \multicolumn{4}{|c|}{ The length of each wall times the height, all exterior walls } & \multicolumn{3}{|c|}{ The length of each wall times the height, all interior walls } \\
\hline \multirow[t]{3}{*}{2} & \multicolumn{7}{|c|}{ PRINT LAYER AND SPEED PARAMETER } \\
\hline & Wall thickness $(\mathbf{c m})^{*}$ & 00 & \multicolumn{3}{|c|}{ Layer height $(\mathrm{cm})$ * } & Print speed $(\mathrm{cm} / \mathrm{s})$ * & 00 \\
\hline & $\begin{array}{l}\text { The width of each print layer } \\
\text { recommended) }\end{array}$ & & \multicolumn{3}{|c|}{$\begin{array}{l}\text { The height of each print layer }(2 \mathrm{~cm} \\
\text { is recommended }\end{array}$} & $\begin{array}{l}30 \mathrm{~cm} / \mathrm{s} \text { is recommended. (Min } 1 \\
\text { printer can do max } 100 \mathrm{~cm} / \mathrm{s} \text {, but mate } \\
\text { such speed will be a challenge) }\end{array}$ & $\begin{aligned} \mathrm{cm} / \mathrm{s} \\
\text { cals fo: }\end{aligned}$ \\
\hline \multirow[t]{3}{*}{3} & \multicolumn{7}{|l|}{ ECONOMIC INPUT } \\
\hline & Price of material per $\mathbf{m} 3$ * & $\mathbf{0 0}$ & \multicolumn{3}{|c|}{ Number of operators * } & $\begin{array}{l}\text { Hourly rate for printer } \\
\text { operators (local currency)* }\end{array}$ & 00 \\
\hline & \multicolumn{7}{|c|}{\begin{tabular}{|l|l}
$\begin{array}{l}\text { The price of } 3 D \text { concrete is typically the } \\
\text { price of normal concrete }+20 \%\end{array}$ & $\begin{array}{l}\text { We recommend } 2 \text { operators, but it } \\
\text { can be done with } 1\end{array}$ \\
try
\end{tabular}} \\
\hline \multirow[t]{5}{*}{4} & \multicolumn{7}{|c|}{ SETUP TIME AND RISC FACTOR } \\
\hline & \multicolumn{3}{|c|}{ Safety factor (percentage, $\%)$ * } & 00 & \multicolumn{2}{|c|}{ Setup time of printer on site (hours) * } & 00 \\
\hline & \multicolumn{4}{|c|}{$\begin{array}{l}\text { Example: } 50 \% \text { increases number of print hours by } 50 \% \text { - let it } \\
\text { reflect the amount of experience you have with } 3 D \text { construction } \\
\text { printing }\end{array}$} & \multicolumn{3}{|c|}{ First time setup will require 8 hours } \\
\hline & \multicolumn{3}{|c|}{ Take down time of printer on site (hours) * } & 00 & \multicolumn{2}{|c|}{$\begin{array}{l}\text { No. of workers involved in setup/take } \\
\text { down * }\end{array}$} & 00 \\
\hline & \multicolumn{4}{|c|}{ First time take down will require 4 hours } & \multicolumn{3}{|l|}{21} \\
\hline \multirow[t]{2}{*}{5} & \multicolumn{7}{|c|}{$\begin{array}{l}\text { TOTAL COST, TIME AND MATERIAL NEEDED } \\
\end{array}$} \\
\hline & \multicolumn{4}{|c|}{ Total cost of project } & & & \\
\hline
\end{tabular}


DR/ Ahmed Saleh /Engineering Research Journal 162 (June 2019) A13- A18
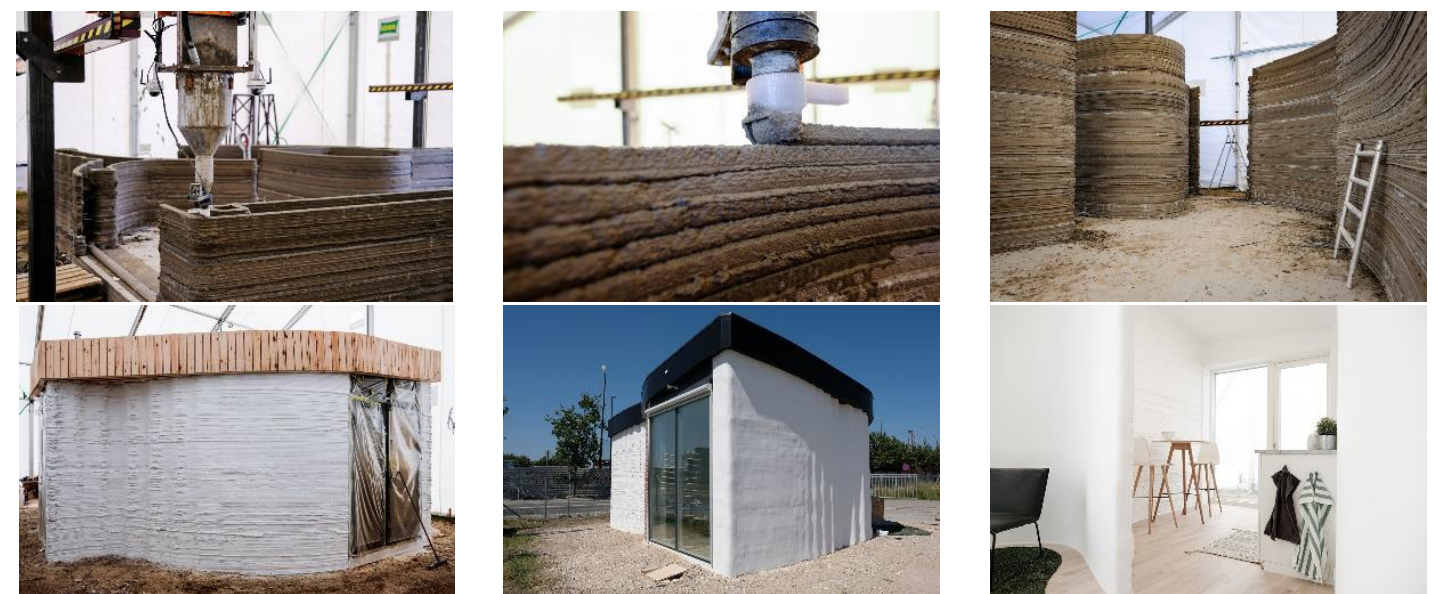

Fig. 12 A Stages of implementation of the BOD Project by COBOD for 3D construction printers and automated processes for the building site. https://cobod.com/the-bod/

Table. 5 3D Construction Printing: A Worldwide overview (researcher)

\begin{tabular}{|c|c|c|}
\hline Cost calculation in 3D printing for BOD project & & $\begin{array}{l}\text { Traditional } \\
\text { methods }\end{array}$ \\
\hline Total $\mathrm{m} 2$ of exterior wall & 35.00 & \\
\hline Double-sided exterior wall $->$ Total area of exterior walls $(\mathrm{m} 2)$ & 70 & \\
\hline Total $\mathrm{m} 2$ of interior wall & 10.00 & \\
\hline Wall thickness $(\mathrm{cm})$ & 5.00 & \\
\hline Layer height $(\mathrm{cm})$ & 2.00 & \\
\hline Print speed $(\mathrm{cm} / \mathrm{s})$ & 20.00 & \\
\hline Material printed per hour $(\mathrm{m} 3 / \mathrm{h})$ & 0.72 & \\
\hline Price of material per $\mathrm{m} 3$ & $2,500.00$ & 2600 L.E \\
\hline Number of operators & 3.00 & \\
\hline Hourly rate (local currency) & 100.00 & \\
\hline Safety factor (percentage, \%) & 50.00 & \\
\hline Setup time of printer on site (hours) & 8.00 & \\
\hline Take down time of printer on site (hours) & 4.00 & \\
\hline No. of people involved in setup/take down & 2.00 & \\
\hline Total $\mathrm{m} 2$ of walls $(\mathrm{m} 2)$ & 45 & \\
\hline Total $\mathrm{m} 2$ of walls to be printed $(\mathrm{m} 2)$ & 80 & \\
\hline Total material use $(\mathrm{m} 3)$ & 4.0 & $4 \mathrm{~m}^{3}$ \\
\hline Hours of print time - theoretical (hours) & 5.56 & \\
\hline Hours of print time needed - including safety factor (hours) & 8.34 & \\
\hline 7 hours of printing $=1$ hour of preperation & 1.19 & \\
\hline Total operator hours for printing (hours) & 26.1 & \\
\hline Total operation hours for project (hours) & 50.1 & \\
\hline Total cost of operators (local currency) & 5.010 .00 & 2200 LE. \\
\hline Total cost per m2 of wall (local currency) & 333.56 & \\
\hline Total cost of concrete (local currency) & 10.000 .00 & 10400 LE. \\
\hline Total cost of project (local currency) & $15,010.00$ & $12600 \mathrm{LE}$. \\
\hline
\end{tabular}


Table (5) illustrates that the cost of BOD project increases by $20 \%$ vs. Traditional methods. This increase represented at the trained labor rather than materials used. As $3 \mathrm{~d}$ printing needs double the cost of labor used in traditional method. This percentage varies according to standards, concrete, the height of the building, and quantities of concrete (the last 2 elements represents the main elements affecting the cost)

N.B: This illustration concerns the application of 3D Printing in Egypt; Given that although labors numbers are reduced, but their costs increase because they are specialized technical workers

\subsection{Advantages and Disadvantages of 3D Printing Technology}

3D printed buildings can easily lay structures using curvilinear forms instead of typical rectilinear forms which makes them a lot more durable. Structures walls are normally hollowed out to allow for utility lines to pass-through and reduce the amount of materials used. Less material not only adds to the durability but also saves a ton of money on the construction costs for the architects and contractors using 3D printing. While the benefits are endless there are still quite a few hurdles holding back this technology. Let's get into the Advantages and Disadvantages of 3D printed construction ${ }^{[19]}$.

\subsubsection{Advantages of 3D Printed Construction}

Reduced Construction Waste. Using 3D printed construction for architectural projects is more environmentally friendly. While using very little energy the printed construction will gnly generate about $30 \%$ of the waste that a normal construction

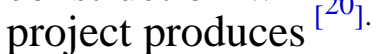

Increased Design Shapes. 3D printing can create design shapes and customization that isn't possible or would be super expensive if done by regular construction. Printers can precisely place small amounts of concrete exactly where needed for complex shapes greatly enhancing an architect's design possibilities.

Reduced Construction Time. Using a 3D printer to complete a building project can massively reduce the construction period.

Lower Construction Costs. 3D printed buildings have much lower building costs than those built with traditional methods because of the reductions in raw material and more importantly labour. An architectural projects labour costs can be reduced by up to $80 \%$ by having most construction completed by 3D printers.

\subsubsection{Disadvantages of 3D Printed Construction}

Building Codes. There are no regulations or processes to get 3D printed buildings approved for residential or commercial use. The government would first need to come up with standards that must be followed as far as electrical, plumbing, structural integrity and public safety codes.

Material Types. The material that can be delivered from the printer head is pretty much limited to just concrete and plastics.

Engineering Compatibility. Very few architects and engineers have took interest in $3 \mathrm{D}$ printed buildings. The additional capabilities that come with the new technology are not being used during the design phase. Traditional blueprints are not compatible for use with a $3 \mathrm{D}$ printer, so the entire design process needs to be handled differently.

3D Printing Technology is Expensive. 3D printing equipment and materials cost make the technology expensive. Industrial grade 3D printers are still expensive costing hundreds of thousands of dollars, which makes the initial expenses of using 
the technology very high. For a single machine, capital investment starts in the tens of thousands of dollars and can increase to as high as hundreds of thousands of dollars

3D Printers Aren't that User-friendly. Because of the excitement and potential around 3D printing technology, 3D printers have come across as easy to use and sound more useful than they really are.

Manufacturing Job Losses. 3D printing technology can make product designs and prototypes in a matter of hours as it uses only one single step. It eliminates a lot of stages that are used in subtractive manufacturing. As a result, it doesn't require a lot of labor cost. As such, adopting 3D printing may decrease manufacturing jobs. For countries that rely on many low skill jobs, the decline in manufacturing jobs could dramatically affect the economy.

\section{3. applying three-dimensional concrete wall printing technology in Egypt}

The traditional construction approach in Egypt has numerous drawbacks. This is evident in the lengthy time frame, the large number of used labour, a high percentage of error and long-distance transportation. All these issues lead to adverse environmental impact and increased construction cost. Such downsides can be addressed efficiently by the rising new technology of Three-dimensional printing Therefore, it will be used SWOT analysis for the application of the 3DP technology in Egypt, and its impact on the Egyptian market with identify the problems and challenges of applying this technology to the Egyptian domestic market.

\subsubsection{Possibilities}

Discussions suggest that the efficiency of construction time may be key to the emergence of this technology in the Egyptian context, but the type and size of the building are important factors to be considered. Thus, it can be argued that 3DP technology may succeed in mass production projects as well as large buildings with limited floors. Has the potential for rapid production and quality, which may compensate for the low quality of work currently experienced among working labor. In addition, the application of this technology will provide an opportunity to regain control in the hands of certified architects, resulting in better internal environmental quality and energy performance in the construction industry in Egypt. Moreover, changing the current building standard in Egypt may improve architectural identity and enhance the final roles of architects in the construction industry.

\subsubsection{Challenges}

The expected challenges to the application of this technology are associated with the cost; noting that comparing brick price (used for typical wall construction) to the cost of reinforced concrete could reach $1 / 4$ and $1 / 2$ if compared to plain concrete (which should be used for 3DP). More challenges are related to the lack of practical knowledge, lack of scientific knowledge, industry/ society rejection of the norm changing methods as well as the lack of stakeholders' interest, trained workforce and cost of importing. as well challenges facing the automated construction systems 
in Egypt, such as lift slab, slip forms ...etc. An additional consideration is related to modification limitations because the design flexibility is limited because of working according to predefined models. It is also impossible to accept any change orders during construction; hence design modifications are not possible. Also, modifications during operation are not possible. Other considerations are related to the costly expenses of durability and maintenance procedures. Moreover, the main concern is that $3 \mathrm{Dp}$ technology is imported rather than capacity-building, which

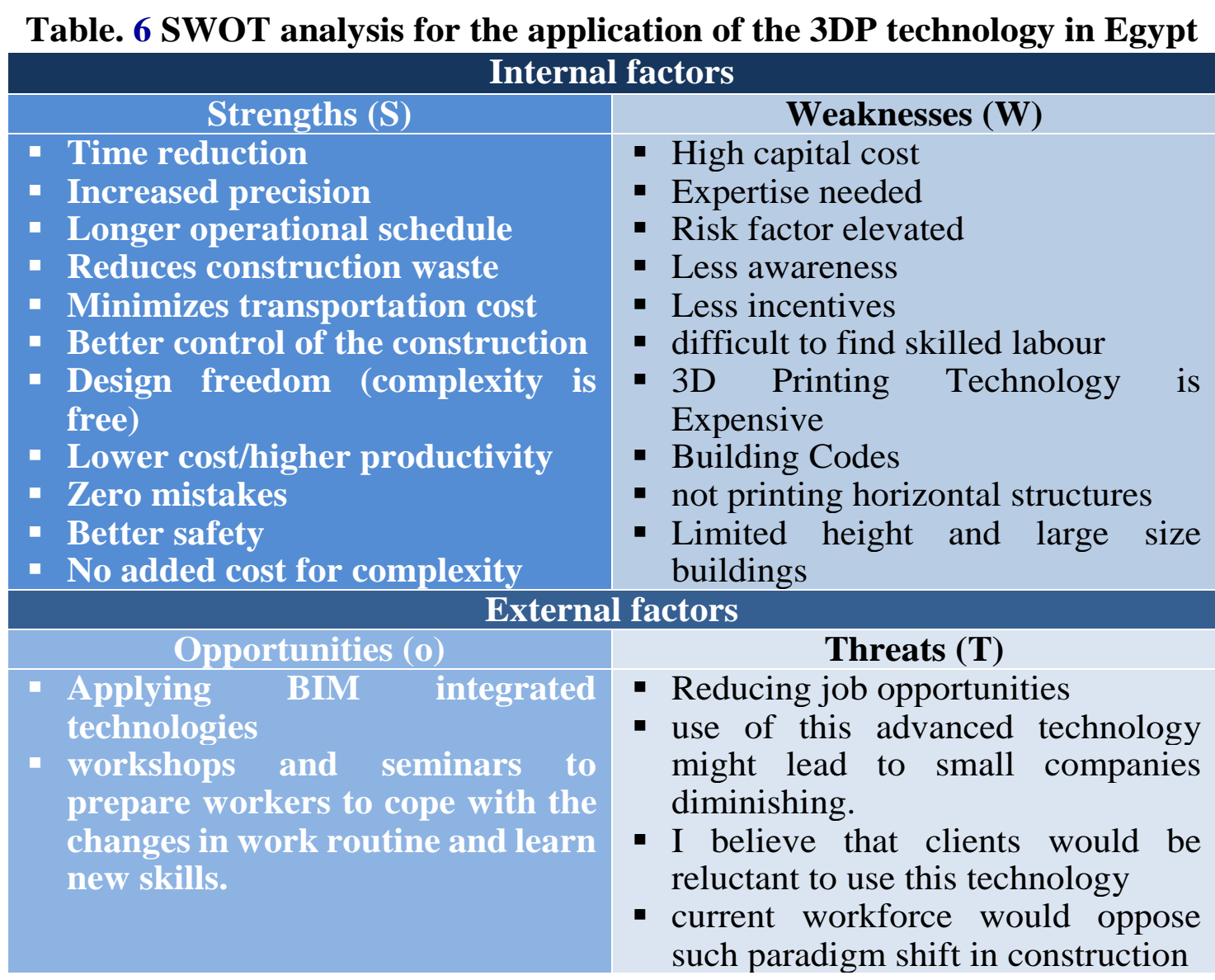

will greatly increase cost.

Accordingly, a SWOT analysis is developed to define external and internal factors that affect the widespread application of this technology in the national context. The former factors are attributed to strengths and weakness of the technology itself, while the latter represent external factors that may be considered as opportunities or threats of applying this technology in the local construction market.

As a result, 3D printing technology has opened new possibilities for industries by enabling faster product design, customization, cost reduction, tangible product testing, and more. However, 3D printing technology has a dark side and is not always the right choice for product development for your development project. 3D machines are still potentially hazardous and wasteful. Moreover, their economic, political, societal, and environmental impacts have not been extensively studied. 


\section{Conclusion}

The 3D printing technology has rapidly changed the views on using concrete as a 3D printable material alone. The requirements and challenges in adopting concrete to $3 \mathrm{D}$ printing have been discussed. 3D printing technique for cementitious material is a promising method that may revolutionize the traditional building and construction processes in terms of apparent benefits in low-cost, high-efficient automatic construction, architectural design freedom, and reduction of labor requirements and risks during construction. This paper has discussed the different types of 3D printing system that are available commercially in terms of their general benefits and drawbacks. The types of 3D printing concrete technologies, research and commercial projects that have practiced the technologies have been listed. The various possibilities of using concrete as a 3D printable material and future of this technology has been analyzed. Large-scale 3D printing processes of cementitious materials are reviewed. They have the potential to reshape the way we think about architectural buildings. However, 3D printing technology still faces certain challenges associated with mechanical strength, reinforcement, curing, durability and correlation properties like flowability, extrudability and buildability. It is a great challenge to study printable cementitious materials compatible with 3D printers.

However, the technology needs more resources to develop faster. The truth behind the $3 \mathrm{D}$ construction printing projects is that none of the completed projects has been competitive so far. There might have been some saving in labor costs and materials, but overall it has not been competitive to the traditional methods of construction. It is evident that many companies and academia are interested in the $3 \mathrm{D}$ concrete printing technology, but there is a lot to be learned on this subject in the near future. The phase of scientific advancement in technology has risen in the past few decades from mobile phones to artificial intelligence. Therefore, the future holds good promises for 3D Concrete Printing.

\subsection{Recommendations}

- Increased cooperation with academia for insights in new and improved 3D concrete printing technologies.

- Increased cooperation with conventional suppliers to support the development of concrete 3D printing.

- Capital and Investments in concrete 3D printing projects should increase with rising popularity of this technology.

- Integrating reinforcements in the 3D printed structure to build high-rise buildings in the future.

- Usage of recycled materials should be increased to build environmentally friendly structures.

- The trends of using concrete 3D printing will increase in the field of architecture for its versatile nature for complex designs.

- through BIM software. This could allow a greater control over all phases of the project, from concept to engineering, with tighter control of time and cost, as well as fewer unforeseen and varied workloads.

- Strategic Implications for Stakeholders As this evolution proceeds, the construction industry will be transformed.

- Companies and governments would do well to prepare for this transformation and to influence it as far as possible to their own. 
${ }^{[1]}$ Chang, S. H. (Shawn H. (2016), 'Exploring the evolution of additive manufacturing industry: a study of stakeholder requirements and architectural analysis of Desktop three-dimensional printing Segment', Massachusetts Institute of Technology. Available at: https://dspace.mit.edu/handle/1721.1/106243 (Accessed: 15 January 2018).

[2] Dana Goldberg (no date) 'History of 3D Printing: It's Older Than You Think, Available at: https://www.autodesk.com/redshift/history-of-3d-printing/ (Accessed: 15 January 2018).

[3] Paul, S. C. et al. (2018), 'A review of 3D concrete printing systems and materials properties: current status and future research prospects', Rapid Prototyping Journal, p. 0. doi: 10.1108/RPJ-092016-0154.

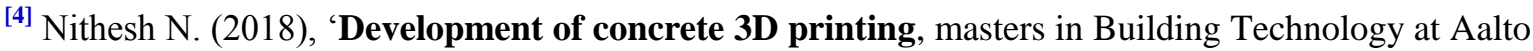
University, 2018.

${ }^{[5]}$ Chen, D. et al. (2015), 'Direct digital manufacturing: definition, evolution, and sustainability implications', Journal of Cleaner Production. Elsevier, 107, pp. 615-625.

${ }^{[6]}$ Roberto Naboni and Ingrid Paoletti. (2015) 'Advanced Customization in Architectural Design and Construction', Springer Cham Heidelberg New York, ISBN 978-3-319-04423-1 (eBook).

[7] 'Spain unveils world's first 3D printed pedestrian bridge made of concrete', 3ders.org. Retrieved 2019-04-16.

${ }^{[8]}$ Building a lunar base with 3D printing / Technology / Our Activities / ESA, Esa.int. 2013-01-31. Retrieved 2019-04-30.

[9] Diaz, Jesus (2013-01-31). 'This Is What the First Lunar Base Could Really Look Like', Gizmodo. Retrieved 2013-02-01.

[10] Wolfs, R. J. M., Bos, F. P. and Salet, T. A. M. (2018) 'Correlation between destructive compression tests and non-destructive ultrasonic measurements on early age $3 \mathrm{D}$ printed concrete', Construction and Building Materials. Elsevier Ltd, 181, pp. 447-454.

[11] Bos, F. et al. (2016), 'Additive manufacturing of concrete in construction: potentials and challenges of 3D concrete printing', Virtual and Physical Prototyping. Taylor \& Francis, 11(3).

${ }^{[12]}$ Nathan Ingraham (2017), 'TU Eindhoven's 3D-printed concrete bicycle bridge first of its kind', Available at: https://www.designboom.com/technology/tu-eindhoven-3d-printed-concrete-bicyclebridge-gemert-09-08-2017/ (Accessed: 22 December 2017).

[13] Marlon A (2015), 'How 3D Printing is Affecting the Construction Industry', Available at: https://www.forconstructionpros.com/blogs/construction-toolbox/blog/12059477/how-3d-printing-isaffecting-the-construction-industry (Accessed: 22 December 2017).

${ }^{[14]}$ Paul, S. C. et al. (2018) 'A review of 3D concrete printing systems and materials properties: Current status and future research prospects', Rapid Prototyping Journal.

${ }^{[15]}$ Hager, I., Golonka, A. and Putanowicz, R. (2016) '3D Printing of Buildings and Building

Components as the Future of Sustainable Construction?', Procedia Engineering, 151, pp. $292-299$.

${ }^{[16]}$ Roussel, N. (2018) 'Rheological requirements for printable concretes', Cement and Concrete Research. Elsevier, (January), pp. 1-10.

${ }^{[17]}$ Li, Z., Wang, L. and Ma, G. (2018) 'Method for the Enhancement of Buildability and Bending

Resistance of 3D Printable Tailing Mortar', International Journal of Concrete Structures and

Materials. Springer Singapore, 12(1). doi: 10.1186/s40069-018-0269-0.

${ }^{[18]}$ Wangler, T. et al. (2016) 'Digital Concrete: Opportunities and Challenges', RILEM Technical Letters, 1, p. 67. doi: 10.21809/rilemtechlett.2016.16.

${ }^{[19]}$ Wolfs, R. J. M., Bos, F. P. and Salet, T. A. M. (2018) 'Early age mechanical behavior of 3D printed concrete: Numerical modelling and experimental testing', Cement and Concrete Research. Elsevier, 106(May 2017), pp. 103-116. doi: 10.1016/j.cemconres.2018.02.001.

${ }^{[20]}$ Wolfs, R. J. M., Bos, F. P. and Salet, T. A. M. (2018) 'Early age mechanical behavior of 3D printed concrete: Numerical modelling and experimental testing', Cement and Concrete Research. Elsevier, 106(May 2017), pp. 103-116. doi: 10.1016/j.cemconres.2018.02.001. 